\title{
Malaysian Malay’s Perspective on Printed Sexy Advertisement
}

\author{
Uma Devi Krisnan ${ }^{1} \&$ Ernest Cyril de Run ${ }^{2}$ \\ ${ }^{1}$ Faculty of Business, Accounting and Management, SEGi University, Kota Damansara, Malaysia \\ ${ }^{2}$ Business Management Department (Marketing), Faculty of Economics and Business, University Malaysia \\ Sarawak, Malaysia \\ Correspondence: Uma Devi Krisnan, Faculty of Business, Accounting and Management, SEGi University, Kota \\ Damansara, Malaysia. E-mail: umadevikrisnan@segi.edu.my
}

Received: April 21, 2016

Accepted: May 30, 2016

Online Published: July 18, 2016

doi:10.5539/ijbm.v11n8p145

URL: http://dx.doi.org/10.5539/ijbm.v11n8p145

\begin{abstract}
This paper sets out to extend current knowledge on reaction towards different levels of sexiness in printed advertisement by Malaysian Malays. This research test these affected based on male models in the communication and advertising literature on Malay in Malaysia utilizing questionnaire based on a set of different levels of sexiness in advertisement. The advertisement used was for non-controversial product (perfume) but some of the advertisement was contentious. Researcher used three levels of advertisements; a fully clothed male model, a revealing attire male model, and a partially sexy male model. Data collected was analyzed using Mean and compared against the response of male and female respondents. Findings indicates that Malay respondents preferred to view fully clothed advertisement followed by revealing attire and partially sexy advertisements. Main limitation for this research is the study used three different advertisements, but each respondents saw only one. Future research will benefit from further improvement (use female and both male and female models) and replication to other ethnic groups. Implications for business are then provided in this paper.
\end{abstract}

Keywords: advertising, levels of sexiness, ethnicity, Malay, Malaysia

\section{Introduction}

Malaysia is a multiethnic country and Malay is the majority ethnic group. Malay refers to a person who practices Islam and Malay traditions and speaks the Malays language (Asmah, 1983). The Malays are people migrated from the Hoabhinh region in the waves of the Malaya Peninsula, Sumatra, Borneo and the Philippines during the Mesolithic-Era and Neolithic-Era (Jamal, 2003). Today, Malays who are Muslims make up Malaysia's largest ethnic group with the population 50.1\% (Department of Statistics Malaysia, 2010).

Sexy advertisement is considered to be offensive sometimes, depending upon the culture and the country. But it's the sex appeal is not offensive, then it is generally acceptable in society (Hultin \& Lundh, 2004). There is evidence suggesting that groups of individuals vary in their reactions to sexual stimuli (Morrison \& Sherman, 1972). Most Malaysians, especially those who are of low intensity of belief, including Muslims, do not think that sex related products are offensive (Fam et al., 2004). Consequently, International advertisers often face an obvious dilemma when they introduce a foreign product into the country with a Muslim segment of the population (Waller et al., 2005).

Advertisement often touches the borderline of the forbidden, with the purpose of attracting attention (Hultin \& Lundh, 2004). The border for the standard is pushed all the time. In Malaysia, the government has revised the strict Malaysian Advertising Code of Ethics for Television and Radio to control the content of commercials and advertisement by restricting the use of sex to sell products and services (Advertising Standards Authority Malaysia, 2008). Scenes involving models undressing are not allowed and woman model must be covered from the neckline to below the knees. Other restrictions include scenes which suggest intimacy, disco scenes, feminine napkins, and kissing between adults (Johnson, 2007).

This study looks at the Malaysian Malay's reactions towards the used of sexy cues in a printed advertisement where the product is not offensive. The rest of the paper is organized as follows: first discussion of the relevant literature is presented; then the methodology is discussed; findings presented; and finally the paper concludes with a discussion of academic implications and areas for future research. 


\section{Literature Review}

Sex in advertising refers to the use of sexual interest as a tool of persuasion to draw attention to a particular item of consumption (Udejinta, 2015). It is also considered one of the most influential tools of marketers and especially advertising (Hultin \& Lundh, 2004). Numerous findings indicated that sexy elements in advertisement, are more engaging, involving and interesting than nonsexual advertisement (Reichert et al., 2001). Moreover, sex appeal in advertising can be effective for attracting initial attention (Reid \& Soley, 1981), enhancing recall (Steadman, 1969), evoking emotional responses (Courtney \& Whipple, 1983), increasing persuasion (LaTour et al., 1990) and buying intention (Grazer \& Keesling, 1995).

In many respects, Malaysia is relatively a more conservative country compared with other Asian countries such as Thailand, Singapore, and Indonesia (Chow-Hou et al., 1995). The findings of previous researchers compare the portrayal of both men and women sexes in television advertising from Singapore and Malaysia (Chow-Hou et al., 1995). Even respondents were established differently; researcher found that the characters in both countries' advertisement were found to be stereotyped.

Malaysian Code of Advertising Practice as a regulation that was instituted by the government is based on the assumption that not all Malaysians are prepared to fully accept all aspects of Western culture (Deng et al., 1994). In 1981, the Ministry of Home Affairs came out with a stark reminder to the press on the advertisements published. The Ministry hit in the press for publishing photographs and advertisements that were considered unsuitable for a general public. However, while advertisers were transparently in violation, no action was taken against them. Malaysia also has advertising codes that prohibit the use of foreign models in their advertisements yet Aiswarya Rai, Shah Rukh Khan, and Christiano Ronaldo is seen on television in Malaysia (Chow-Hou et al., 1995; Waller \& Fam, 2000).

The fact that sex is such an instinctive need makes it a very attractive tool for advertisers (Pugh, 2007). However, the Malaysian government has been relaxing the rules on sex related advertisements because of the rise in sexually related diseases, especially AIDS (Waller \& Fam, 2000). In order to design an effective and acceptable advertisement, marketers should be responsive to the various cultural differences and different ethnic group in the country (Waller et al., 2005). Hence, marketing experts acknowledged that various rules and regulations in Muslim countries be able to restrict global advertisement (Walters, 2008). Media are not permitted to broadcast advertisements with the content of sex appeals and emotional, using female models with sexy attire in order to grab customer attention (Akhter et al., 2011). On the other side, consumer behavior and response towards advertisements can be affected by religious attitudes (Rice, 2002).

\section{Methodology}

The population in Malaysia is 14,322,100 of Malays; which $48.98 \%$ male and $51.28 \%$ female for the year 2010 (Department of Statistics Malaysia, 2010). Sample size was predetermined by the consideration of the pseudo factorial design used. This study uses ethnic group (Malay) x 2 gender of respondents (male and female) x 3 advertisement types (fully clothed, revealing attire and partially sexy) factorial designs. Researcher uses the purposive sampling method in this study (Zikmund, 2003). This study obtained 163 male and 161 female respondents, whom were selected from various parts where in Malaysia. There are three printed advertisements, Ad 1 contained a fully clothed male model, Ad2 contained revealing attire male model and Ad 3 contained a partially sexy male model was used (Refer Figure 1).

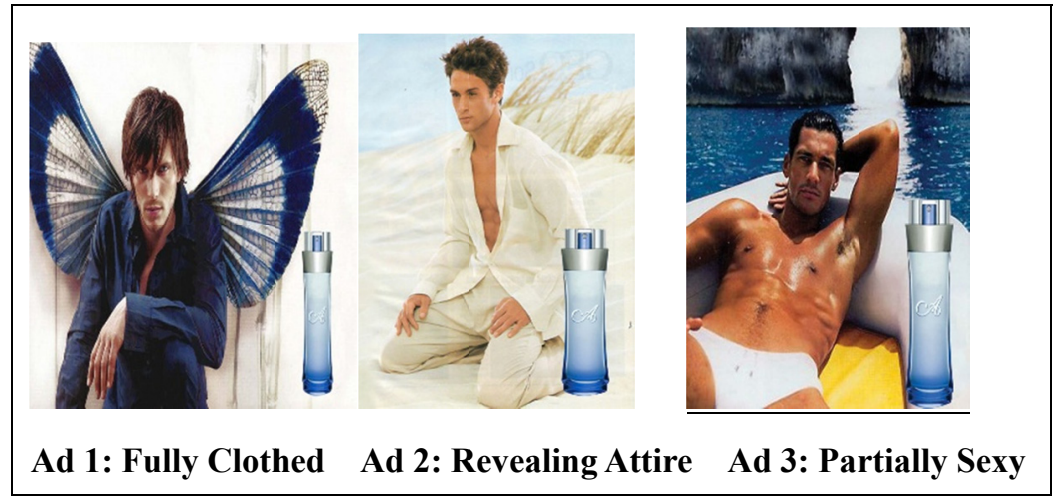

Figure 1. Advertisements used 
The questionnaire were presented in English. The questionnaire had two sections: the first was for demographic; the second covered four propositions which is attitude towards advertisement (Henthorne et al., 1993), attitude towards product (Maheswaran \& Sternthal, 1990), purchase intention (Maheswaran \& Sternthal, 1990), and word of mouth (Becker \& Kaldenberg, 2000). The questionnaires chosen for this research used six-point scale questionnaires. Six-point scale was used as it is forces respondent to choose a point either before or after the middle point which is non-existent (Chang, 1994; Prendergast et al., 2009). The six anchors used in this interval scale are strongly disagree (1) to strongly agree (6). Six-point scale works better in such condition where it eliminates such a pattern, as if it forces respondent to choose a point either before or after the middle point which is non-existent. At the same time using a six-point scale would also result in higher validity and reliability of the findings (Chang, 1994; Malhotra, 2004). Data was analyzed using Mean and T-test.

\section{Findings}

The respondents profile is summarized in Table 1. The mean score for variables tested by advertisement types is depicted in Table 2. T-test by gender and advertisement types then presented in Table 3, 4, and 5.

Table 1. Respondent's profile

\begin{tabular}{llll}
\hline Variable & & Frequency & Percentage \\
\hline Gender & Male & 163 & 50.3 \\
Age & Female & 161 & 49.7 \\
& $10-19$ years old & 28 & 8.6 \\
& $20-29$ years old & 96 & 29.6 \\
& $30-39$ years old & 95 & 29.3 \\
& $40-49$ years old & 74 & 9.6 \\
Marital Status & 50 years old and above & 31 & 45.4 \\
& Single & 147 & 53.7 \\
Highest Education Level & Married & 174 & 0.9 \\
& Divorced & 3 & 3.1 \\
& No Formal Education & 10 & 2.8 \\
& Primary Level & 9 & 68.5 \\
Advertisement Type & Secondary Level & 222 & 14.2 \\
& Diploma & 46 & 7.4 \\
& Degree & 24 & 4.0 \\
& Postgraduate Degree & 13 & 33.3 \\
\end{tabular}

Respondents profiles show that the highest percentage the respondents categories from 20 - 39 years old. At the same time, there are 161 female and 163 male respondents have participated in this research. This research shows that majority of the respondents can be categories as married (53.7\%) respondents and secondary level $(68.5 \%)$ as their highest education level. 
Table 2. Mean for sexy advertisement variables with gender and advertisement types

\begin{tabular}{|c|c|c|c|c|c|c|c|}
\hline \multirow[t]{2}{*}{ Advertisement Type } & \multirow[t]{2}{*}{ Variable } & \multicolumn{2}{|c|}{ Overall } & \multicolumn{2}{|l|}{ Male } & \multicolumn{2}{|c|}{ Female } \\
\hline & & Mean & S.D. & Mean & S.D. & Mean & S.D. \\
\hline \multirow[t]{4}{*}{ Fully Clothed } & Attitude towards Advertisement & 4.07 & 0.79 & 3.97 & 0.67 & 4.17 & 0.88 \\
\hline & Attitude towards Product & 3.90 & 0.70 & 3.71 & 0.64 & 4.11 & 0.71 \\
\hline & Purchase Intention & 3.47 & 0.88 & 3.22 & 0.76 & 3.72 & 0.94 \\
\hline & Word of Mouth & 3.87 & 0.96 & 3.57 & 0.98 & 4.17 & 0.85 \\
\hline \multirow[t]{4}{*}{ Revealing Attire } & Attitude towards Advertisement & 3.60 & 0.67 & 3.76 & 0.56 & 3.44 & 0.73 \\
\hline & Attitude towards Product & 3.72 & 0.69 & 3.90 & 0.70 & 3.53 & 0.64 \\
\hline & Purchase Intention & 3.32 & 0.97 & 3.52 & 0.92 & 3.12 & 0.98 \\
\hline & Word of Mouth & 3.61 & 0.97 & 3.55 & 0.97 & 3.67 & 0.97 \\
\hline \multirow[t]{4}{*}{ Partially Sexy } & Attitude towards Advertisement & 3.00 & 0.82 & 3.16 & 0.96 & 2.85 & 0.61 \\
\hline & Attitude towards Product & 3.33 & 0.64 & 3.34 & 0.70 & 3.31 & 0.57 \\
\hline & Purchase Intention & 2.78 & 0.85 & 2.87 & 0.81 & 2.69 & 0.89 \\
\hline & Word of Mouth & 3.25 & 0.85 & 3.33 & 0.93 & 3.16 & 0.78 \\
\hline
\end{tabular}

The mean score for all the attitudes and behavioural factors indicates more than 3.00 except purchase intention for partially sexy advertisement (M: 2.78; S.D.: 0.85). Results indicate that, the respondents agreed to almost all the attitude factors influenced behaviours intention towards viewing sexy advertisement. Attitude towards advertisement factors indicate the highest mean score (M: 4.07; S.D.: 0.79) for fully clothed advertisement. Therefore, female respondents more focus on fully clothed advertisement compares to revealing attire and partially sexy advertisement.

Table 3. Independent sample test for fully clothed advertisement for ethnicity (Malay) by gender

\begin{tabular}{llll}
\hline Variable & t & df & Sig. (2-tailed) \\
\hline Attitude towards advertisement & -1.329 & 97.37 & 0.187 \\
Attitude towards product & -3.130 & 104.05 & $0.002^{*}$ \\
Purchase intention & -3.061 & 100.09 & $0.003^{*}$ \\
Word of mouth & -3.396 & 104.79 & $0.001^{*}$ \\
$*=$ significant difference & & & \\
\hline
\end{tabular}

Table 4. Independent sample test for revealing attire advertisement for ethnicity (Malay) by gender

\begin{tabular}{llll}
\hline Variable & t & df & Sig. (2-tailed) \\
\hline Attitude towards advertisement & 2.569 & 101.46 & 0.012 \\
Attitude towards product & 2.888 & 107.29 & $0.005^{*}$ \\
Purchase intention & 2.194 & 107.61 & 0.030 \\
Word of mouth & -0.690 & 107.99 & 0.492 \\
$*$ =significant difference & & & \\
\hline
\end{tabular}

Table 5. Independent sample test for partially sexy advertisement for ethnicity (Malay) by gender

\begin{tabular}{llll}
\hline Variable & t & df & Sig. (2-tailed) \\
\hline Attitude towards advertisement & 1.978 & 88.02 & 0.051 \\
Attitude towards product & 0.177 & 100.58 & 0.860 \\
Purchase intention & 1.100 & 103.17 & 0.274 \\
Word of mouth & 0.994 & 100.93 & 0.322 \\
$*=$ significant difference & & & \\
\hline
\end{tabular}

\section{Discussion}

The objective of this study is to provide an overview of the reaction of Malay respondents towards different levels of printed sexy advertisements. The findings shows that the overall view of Malay respondents preferred to view fully clothed male model advertisement from the perspective of attitude and behavior. Attitudes towards the advertisement, attitudes towards the product, word of mouth and purchase intentions mean scores fall lesser 
and lesser when the levels of sexiness increase in the advertising. This may be due to the fact that the printed advertisement is for perfume and thus the acceptance of fully clothed male model and rejection of revealing attire male model and partially sexy male model. Its shows that, Malaysian Malay respondents are more conservative and not always accepts the sexy content in advertisements. When the advertisement depicts a slightly sexy model, immediately the overall response drops. This results is in line with Islamic values and beliefs, at the same time, scholars consider an Islamic women's chest, hips, neck, or basically her whole body as zeenah, all of which should be covered to avoid enticing the opposite sex (Sechzer, 2004).

This reveals the thinking of the Malaysian Malay community's as a whole, which influence their own culture and practices. This is because the Malay culture deems as overtly sexual will be considered as unacceptable and even unethical (LaTour \& Henthorne, 1993). Malays in Malaysia are still very much conservative. Advertisement that contains a strong sexual elements (partially sexy advertisement) in this research is significantly less favorable attitude towards advertisement, purchase intention and word of mouth than an advertisement that contain a mild sexual appeal (revealing attire advertisement).

In this research, results clearly shows that Malays in Malaysian are not ready to accept the mild sex appeal (open shirt displaying the male model's chest) in advertisements. Nevertheless, overdone sex appeal in advertising can be offensive for this target audiences, therefore causing the advertisement to be ineffective (Liu et al., 2006). The sexual appeal in advertisement is not always perceives as acceptable from a moral and cultural point of view (Manceau \& Desbordes, 2006). This means looking at overt sexuality image in advertisement may be believed as unacceptable for Malays in Malaysia.

Past researcher indicated that the use of models of the opposite gender in advertisement is more effective (Belch et al., 1981; Simpson et al., 1996). In this research, there are some evidence to shows the differences. Both Malay women and men respondents seemed to indicate that they preferred to talk about fully clothed advertisement and revealing attire advertisement over partially sexy advertisement. If placed in ranking order, both Malay men and women prefer fully clothed advertisement followed by revealing attire advertisement and followed by partially sexy advertisement. This is itself is a dilemma and it may indicate the society's normative beliefs and subjective norms impacting the answers by respondents as there was no significant difference between responses for revealing attire and partially sexy advertisements. Nevertheless the findings support past research that showed that increasing of sex appeal in advertisements will be seen as offensive and therefore less effective to females (Fetto, 2001; Judd \& Alexander, 1983).

Therefore, advertisers should understand that culture and adapt the advertisements to reflect its values in order to be successful, because consumers tend to respond to advertising messages that are congruent with their culture (Zhang \& Gelb, 1996).

\section{Conclusions}

This research has successfully achieved its objective to identify male and female Malay respondent's reaction towards fully clothed, revealing attire and partially sexy male model advertisement. Reaction that were assessed were attitude to the advertisement, attitude towards product, purchase intention and word of mouth. The finding shows that there are differences between male and female respondent's responses in the advertisement.

\subsection{Managerial Implication}

If the product is to be used mainly by women, then management should utilized male models in the utilized male models in the advertisement it they wish to use the power of sexiness in advertisements. Managers must take heed of the level of sexiness and use sexy male models appropriately. If the target market of the business is Malays, the use of fully clothed is reasonable. Anything more may just reduce the effectiveness of such advertisements.

\subsection{Limitation}

This study used three different advertisement, but each respondent only saw one. There was no opportunity for direct comparison of advertisements by each respondent and they might react clearly for that specific advertisement only. This study also inability to know whether the respondent was dishonest in order to appear socially acceptable. Aside from that, this study only focused at one gender as the model and as such may have an effect on the responses by gender.

\subsection{Future Research}

The research only focuses on one ethnic group, which is Malay ethnic group. Therefore other ethnic group such as Chinese, Indian and Native ethnic groups in Malaysia can focus on. Additional limitation can apply on 
different levels of sexiness to identify there are any changes in attitudes and behavioral due to the increased levels of sexy in the advertisement of high involvement to determine customer reaction towards different levels of sexy advertisement. Further replications can look at the different levels of sexiness to see if there are any changes in responses due to the increased levels of sexy in the advertisement. Studies can also take into account normative and subjective norms and its impact on such advertisements.

\section{References}

Advertising Standards Authority Malaysia. (2008). Malaysian code of advertising practice (3rd ed., pp. 99).

Akhter, W., Abassi, A. S., \& Umar, S. (2011). Ethical issues in advertising in Pakistan: An Islamic perspective. World Applied Sciences Journal, 13(3), 444-452. Retrieved from http://idosi.org/wasj/wasj13(3)/10.pdf

Asmah, O. (1983). The Malay people of Malaysia and their languages. Kuala Lumpur: Dewan Bahasa Dan Pustaka.

Becker, B. W., \& Kaldenberg, D. O. (2000). Factors influencing the recommendation of nursing homes. Marketing Health Services, 20(4), 22-28.

Belch, M. A., Barbro, E. H., George, E. B., \& Jerry, K. (1981). Psychophysiological and cognitive responses to sex in advertising. Advance in Consumer Research, 9, 424-427.

Chang, L. (1994). A psychometric evaluation of 4-point and 6-point Likert-type scales in relation to reliability and validity. Applied Psychology Measurement, 18(3), 205-215.

Chow-Hou, W., Mei-Lan, C., \& Siok-Kuan, T. (1995). Sex role portrayal in television advertising: A comparative study of Singapore and Malaysia. International Marketing Review, 12(1), 49-64.

Courtney, A., \& Whipple, T. (1983). Sex Stereotyping in Advertising. Canada: Lexington Books.

Deng, S., Jivan, S., \& Hassan, M. L. (1994). Advertising in Malaysia: A cultural perspective. International Journal of Advertising, 13(2), 153-166.

Department of Statistics Malaysia, J. (2010). Buku Maklumat Penerangan Statistic Handbook Malaysia 2010: Percetakan Nasional Malaysia Berhad.

Fam, K. S., Waller, D. S., \& Erdogan, B. Z. (2004). The influence of religion on attitudes towards the advertising of controversial products. European Journal of Marketing, 38(5/6), 537-555.

Fetto, J. (2001). Where's the lovin'? American Demographics, 23(2), 10-11.

Grazer, W. F., \& Keesling, G. (1995). The effect of print advertising's use of sexual themes on brand recall and purchase intention: A product specific investigation of male responses. Journal of Applied Business Research, 11(3), 47-58.

Henthorne, T. L., LaTour, M. S., \& Nataraajan, R. (1993). Fear appeals in print advertising: An analysis of arousal and ad response. Journal of Advertising, 22(2), 59-69.

Hultin, M., \& Lundh, E. (2004). Sex in advertising: How it influences young men and women. Bachelor's Thesis, 4, 167.

Jamal, A. (2003). Marketing in a multicultural world: The interplay of marketing, ethnicity and consumption. European Journal of Marketing, 37(11/12), 1599-1620.

Johnson, L. (2007). Malaysia press, media, TV, radio, newspapers.

Judd, B. B., \& Alexander, M. W. (1983). On the reduced effectiveness of some sexually suggestive ads. Journal of the Academy of Marketing Science, 11(2), 156-168.

LaTour, M. S., Pitts, R. E., \& Snook Luther, D. C. (1990). Female nudity, arousal, and ad response: An experimental investigation. Journal of Advertising, 19(4), 51-62.

Liu, F., Li, J., \& Cheng, H. (2006). Sex appeal advertising: Gender differences in Chinese consumers' Asia pacific. Journal of Marketing and Logistics, $18,1$.

Maheswaran, D., \& Sternthal, B. (1990). The effects of knowledge, motivation, and type of message on ad processing and product judgments. Journal of Consumer Research, 17, 66-73.

Malhotra, N. K. (2004). Marketing research: An applied orientation. London: Prentice Hall International.

Manceau, D., \& Desbordes, E. T. (2006). Are sex and death taboos in advertising? An analysis of taboos in advertising and a survey of French consumer perceptions. International Journal of Advertising, 25(1), 9-33. 
Morrison, B. J., \& Sherman, R. C. (1972). Who responds to sex in advertising. Journal of Advertising Research, 12(2), 15-19.

Prendergast, G., Liu, P. Y., \& Poon, D. T. Y. (2009). A Hong Kong study of advertising credibility. Journal of Consumer Marketing, 26(5), 320-329.

Pugh, J. (2007). "Sex sells"-how and why?

Reichert, T., \& Alvaro, E. (2001). The effects of sexual information on ad and brand processing and recall. Southwestern Mass Communication Journal, 17(1), 9-17.

Reichert, T., Heckler, S. E., \& Jackson, S. (2001). The effects of sexual social marketing appeals on cognitive processing and persuasion. Journal of Advertising, 30(1), 13-27.

Reid, L. N., \& Soley, L. C. (1981). Another look at the 'decorative' female model: The recognition of visual and verbal advertisement components. Current Issues and Research in Advertising, 122-133.

Rice, G. A. M. (2002). Assessing long-term promotional influence on market structure; the implication of Islam for advertising messages. Journal of Euro Marketing, 11(3), 1-16.

Simpson, P. M., Steve, H., \& Brown, G. (1996). Male nudity in advertisements: A modified replication and extension of gender and product effects. Journal of the Academy of Marketing Science, 24(3), 257.

Steadman, M. (1969). How sexy illustrations affect brand recall. Journal of Advertising, 9(1), 15-19.

Udejinta, M. O. (2015). Influence of sex appeal advertising on brand patronage among students of selected Nigerian University. International Journal of Management Sciences, 5 (11), 759-770.

Waller, D. S., \& Fam, K. S. (2000). Cultural values and advertising in Malaysia: Views from the industry. Asia Pacific Journal of Marketing and Logistics.

Waller, D. S., Fam, K. S., \& Erdogan, B. Z. (2005). Advertising of controversial products: A cross-cultural study. Journal of Consumer Marketing, 2(1), 6-13.

Walters, P. W. (2008). Global strategy in the international advertising industry. International Business Review, 17, 236-249.

Zhang, Y., \& Gelb, B. (1996). Matching advertising appeals to culture: The influence of product use conditions. Journal of Advertising, 25, 29-46.

Zikmund, W. G. (2003). Business research method (7th ed.). US: Thomson South- Western.

\section{Copyrights}

Copyright for this article is retained by the author(s), with first publication rights granted to the journal.

This is an open-access article distributed under the terms and conditions of the Creative Commons Attribution license (http://creativecommons.org/licenses/by/3.0/). 